\title{
SOIL BIOENGINEERING DAN PERANANNYA DALAM GEOLOGI LINGKUNGAN
}

\section{SOIL BIOENGINEERING AND ITS ROLE IN ENVIRONMENTAL GEOLOGY}

\author{
Iwan G. Tejakusuma ${ }^{1}$
}

\begin{abstract}
ABSTRAK: Pengetahuan tentang geologi lingkungan memegang peranan yang sangat penting dalam setiap perencanaan pembangunan dan aktivitas manusia yang memanfaatkan lahan. Khususnya dalam pembangunan infrastruktur atau keperluan lainnya maka pembukaan lahan dan pemotongan lereng tidak dapat dihindarkan. Akibatnya, bahaya yang mungkin terjadi diantaranya adalah erosi dan ketidakstabilan lereng. Untuk mencegah erosi dan ketidakstabilan lereng, salah satu upaya yang dilakukan adalah penerapan teknik soil bioengineering. Teknik ini menggunakan vegetasi untuk keperluan fungsi tersebut. Penerapan teknik ini memerlukan pemikiran yang serius dan hati hati terutama dalam hal fungsinya untuk meningkatkan kestabilan lereng.
\end{abstract}

Kata kunci: environmental geology, soil bioengineering, erosion, slope stability.

ABSTRACT: Knowledge of the geological environment plays a very important role in any development planning and human activities that utilize the land. Particularly in infrastructure development or other purposes, the clearing and cutting of the slope cannot be avoided. As a result, the hazard that may occur include erosion and slope instability. To prevent erosion and slope instability, one of the efforts is the application of soil bioengineering techniques. This technique uses vegetation for the purpose of the efforts. The application of this technique requires serious thought and careful application, especially in terms of its function to improve slope stability.

Keywords: capacity, tsunami disaster, MCE, SIG, coastal Cilegon.

\section{PENDAHULUAN}

Aktivitas manusia di alam kerap dapat menimbulkan kerusakan dan gangguan lingkungan yang berakibat pada lingkungan hidup manusia itu sendiri. Kondisi geologi tempat tinggal dan aktivitas manusia perlu dikenali dan dipelajari dengan baik agar akibat lingkungan yang terjadi dapat diminimalisasi.

1. PTRRB - TPSA - BPPT, JI. M. H. Thamrin No. 8, Jakarta 10340.

email: itejakusuma@yahoo.com
Menurut Bell (2001), geologi lingkungan adalah aplikasi dari prinsip-prinsip geologi terhadap permasalahan yang timbul akibat eksploitasi lingkungan fisik dimana manusia berada. Geologi lingkungan bukan hanya mencakup dampak yang ditimbulkan oleh manusia pada lingkungan geologi namun juga dampak lingkungan geologi terhadap manusia. Sebagai contohnya adalah bencana alam seperti letusan gunung api, gempa bumi, longsor dan banjir yang terjadi bukan karena aktivitas manusia namun dapat menimbulkan kerusakan lingkungan dimana 
manusia berada. Demikian pula sebaliknya, kegiatan manusia dapat secara signifikan memberikan dampak pada lingkungan. Studi tentang geologi lingkungan sangat penting terutama dalam perencanaan pembangunan. Perhatian utamanya adalah pada bahaya geologi, dan bagaimana mengurangi dampak negatif yang dapat terjadi pada manusia akibat bahaya tersebut. Untuk keperluan tersebut, pengetahuan tentang kondisi geologi sangatlah penting.

Aktivitas manusia sering merubah kondisi lingkungan geologi seperti perubahan lahan untuk berbagai keperluan seperti misalnya, pertanian, perkebunan, perumahan, transportasi jalan, industri, drainase, fasilitas sosial dan fasilitas umum. Dalam kegiatan pembangunan sering terjadi adanya pembukaan lahan yang merubah morfologi atau kondisi permukaan lahan tersebut dari bentuk aslinya menjadi bentuk yang disesuaikan dengan kebutuhan kegiatan itu sendiri. Pembukaan lahan, pemotongan lereng tidak dapat dihindarkan apabila diperlukan. Berbagai upaya meminimalisasi dampak akibat perubahan tersebut juga dilakukan baik dengan cara struktur maupun non struktur. Dalam tulisan ini akan dibahas tentang soil bioengineering sebagai salah satu upaya dalam menjaga kondisi lahan. Upaya ini merupakan upaya non struktur.

\section{METODE}

Studi tentang soil bioengineering dan perannya dalam geologi lingkungan dilakukan dengan beberapa langkah dan metode sebagai berikut:

- Melakukan studi pustaka dan literatur baik data, informasi, maupun penelitian sebelumnya yang telah dilakukan dari penelusuran literatur berupa jurnal, buku dan dari website.

- Melakukan studi lapangan dan pengamatan pada lokasi jalan tol hal yang berkaitan dengan penerapan teknik soil bioengineering.
- Mendeskripsikan soil bioengineering dan aspek-aspek yang berkaitan.

- Melakukan deskripsi data yang telah didapat dan menguraikan peranan soil bioengineering.

\section{HASIL DAN PEMBAHASAN}

\subsection{Soil Bioengineering}

Soil bioengineering adalah teknik penggunaan tanaman hidup untuk keperluan beberapa fungsi rekayasa (https:// en.wikipedia.org/). Teknik ini dipandang sebagai cara yang efektif untuk mengatasi lahan yang tidak stabil atau mencegah erosi. Teknik ini telah digunakan di berbagai tempat di belahan dunia sejak lama. Menurut Morgan dan Rickson (1995), bioengineering adalah penggunaan berbagai bentuk vegetasi baik satu tanaman maupun beberapa jenis tanaman atau juga kombinasi dengan bahan tanaman yang telah mati dan atau konstruksi teknik sipil yang untuk menstabilisasi lereng dan mencegah erosi. Penggunaan vegetasi dan kombinasinya tersebut itulah yang disebut sebagai bioengineering dengan tujuan untuk stabilisasi lereng dan pengendalian erosi. Soil bioengineering diaplikasikan dengan menggunakan tanaman hidup dan bagian tanaman baik sendiri maupun bersamaan dengan material tanaman yang sudah mati ataupun struktur konstruksi tertentu yang berfungsi sebagai pendukung kondisi tanah dan mencegah pergerakan tanah. Material tanaman seperti potongan tanaman, batang, diletakkan pada permukaan tanah atau ke dalam tanah yang dapat dikombinasikan juga dengan material lain seperti batuan, kayu, bahan geosintetik, geokomposit ataupun produk pabrikan lainnya. Menurut Bischetti et al (2012), soil bioengineering adalah suatu disiplin ilmu yang berhubungan dengan penanganan lereng, sungai dan stabilisasi tanggul yang dalam beberapa dekade terakhir telah menjadi semakin populer di seluruh dunia. Teknik ini memiliki karakteristik estetika dan 
ramah lingkungan, sehingga sering diadopsi untuk mendapatkan dampak lingkungan yang rendah terhadap kegiatan perlindungan lahan khususnya dalam bidang arsitektur lansekap dan restorasi lingkungan.

\subsection{Fungsi Dan Efek Struktur Soil Bioengineering}

\section{Soil bioengineering mempunyai} beberapa fungsi dan efek yang diuraikan diantaranya seperti yang akan diterangkan pada berikut ini (https://en.wikipedia.org/). Fungsi dan efek mencakup fungsi teknik, fungsi ekologis, fungsi landscape dan efek ekonomi.

\section{- Fungsi Teknik}

Soil bioengineering mempunyai beberapa fungsi teknik yaitu:

1. Proteksi permukaan tanah dari erosi baik erosi yang disebabkan oleh angin, hujan, kebekuan karena temperatur yang rendah dan aliran air.

2. Proteksi dari terjadinya gerakan tanah tipe tertentu.

3. Mengeliminasi gaya mekanik destruktif.

4. Memperlambat kecepatan aliran permukaan disepanjang tebing.

5. Proteksi dari terpaan angin.

6. Membantu deposisi sedimen.

7. Meningkatkan koefisien kekasaran permukaan tanah sehingga menurunkan potensi pergerakan permukaan tanah.

Selain hal tersebut di atas, fungsi ekologisnya juga penting terutama bila konstruksi rekayasa yang biasa mempunyai keterbatasan dalam hal menangani permasalahan yang ada.

- Fungsi Ekologis

Fungsi ekologis soil bioengineering diantaranya adalah:

Meningkatkan kondisi keairan dengan cara meningkatkan penyerapan air ke dalam tanah dan meningkatkan daya simpan air.

Konsumsi air oleh tanaman.

Drainase di dalam tanah.
Proteksi dari angin.

Proteksi dari polusi udara.

Ameliorasi tanah secara mekanis oleh akar-akar tanaman.

Menyeimbangkan kondisi temperatur pada dekat permukaan tanah dan dalam tanah.

Efek peneduhan.

Meningkatkan konten nutrien dalam tanah sehingga kesuburan tanah menjadi meningkat.

Menyeimbangkan deposisi salju.

Perlidungan terhadap kebisingan.

Peningkatan hasil dari tanaman yang ada disekitarnya.

\section{- Fungsi Bentang Lahan}

Sebagai fungsi bentang lahan, soil bioengineering mempunyai fungsi diantaranya:

1. Pemulihan pada bentang lahan yang rusak akibat bencana atau kegiatan manusia seperti eksploitasi sumberdaya mineral, penimbunan tanah atau material hasil industri atau limbah domestik.

2. Integrasi struktur ke dalam bentang lahan.

3. Pelapis pada struktur struktur yang berbahaya.

4. Pengayaan bentang lahan dengan menciptakan warna, bentuk dan struktur yang baru dengan vegetasi.

\section{- Efek Ekonomi}

Soil bioengineering tidak selalu lebih murah bila dibandingkan dengan teknik struktur konvensional yang biasa digunakan. Namun bila dipandang dari segi waktu atau usianya termasuk perawatannya, maka teknik ini dapat menjadi lebih ekonomis. Secara ekonomi, beberapa keuntungan dari teknik soil bioengineering ini adalah:

1. Biaya yang lebih murah dibandingkan dengan konstruksi sipil.

2. Biaya yang lebih murah dalam hal biaya perawatan dan rehabilitasi.

3. Membuat daerah menjadi hijau kembali pada daerah yang terlantar.

4. Memberikan tambahan pendapatan. Hasil dari kegiatan atau pekerjaan 
soil bioengineering ini adalah sebuah sistem kehidupan yang kemudian berkembang dan keseimbangannya terjaga dengan cara suksesi alami secara sendiri dan dinamis tanpa harus ada enegri tambahan yang mesti diberikan. Keseimbangan yang baik yang hanya memerlukan perawatan yang minimal akan tercapai bila pemilihan vegetasi dan konstruksi dilakukan secara tepat.

\subsection{Pertimbangan Dalam Aplikasi Soil Bioengineering}

Aplikasi soil bioengineering memerlukan beberapa pertimbangan yang tepat agar keberhasilan dari program ini dapat tercapai dan memberikan hasil yang maksimal. Sistem soil bioengineering mempunyai banyak pilihan metode atau cara. Pemilihan dan penerapan teknik soil bioengineering yang tepat akan sangat menentukan dalam keberhasilan dari program ini. Pengetahuan tentang iklim dan vegetasi suatu wilayah, serta sifat tanah adalah faktor yang penting dalam aplikasi ini. Demikian pula drainase, kemiringan lereng dan kondisi tanah pada daerah dengan aktivitas manusia yang tinggi. Aplikasi ini membutuhkan evaluasi dan pengukuran. Desain aplikasi perlu juga mempertimbangkan sejarah dan evolusi kondisi alam, serta kondisi budaya dan sosial lingkungan sekitarnya. Pertimbangan tersebut penting untuk keberhasilan proyek yang dilakukan. Menurut Lewis (2010), syarat minimal yang harus dipertimbangkan dalam penerapan soil bioengineering adalah:

\section{- Kondisi Iklim.}

Kondisi iklim yang perlu dipertimbangkan adalah curah hujan yang mencakup tipe, tingkatan, waktu dan durasinya. Kemudian temperaturnya termasuk temperatur ekstrim yang mungkin terjadi.

\section{- Topografi.}

Kemiringan lereng, bentuk lahan, ketinggian wilayah dan arah paparan sinar matahari. Perlu diingat bahwa iklim di permukaan tanah dapat bervariasi walau hanya dalam jarak yang dekat.
Misalnya kondisi lahan dengan lembah yang menghadap selatan, misalnya, menerima lebih banyak sinar matahari langsung. Hal ini akan menyebabkan temperatur tanah yang lebih tinggi sehingga meningkatkan penguapan dan umumnya kondisi menjadi lebih kering bila dibandingkan dengan lembah yang lebih teduh yang menghadap ke utara. Perbedaan ini akan mempengaruhi tingkat erosi serta komposisi dan tingkat pertumbuhan vegetasi.

\section{- Kondisi Tanah.}

Kondisi tanah mencakup kondisi substrat, permeabilitas air dan akar, kapasitas kelembaban tanah dan ketersediaan unsur hara. Selain itu penting juga untuk mengidentifikasi kondisi di atas dan di bawah atau dalam lokasi pekerjaan soil bioengineering yang mungkin mempengaruhi kegiatan ini dan hal tersebut dimasukkan dalam pertimbangan disain yang akan diterapkan.

\section{- Kondisi Keairan.}

Kondisi keairan yang perlu diperhatikan adalah kondisi sungai yang mungkin terpengaruh oleh erosi di lahan. Kemudian pengamatan pada lokasi lokasi saluran drainase alami dan aliran permukaan yang mungkin mempengaruhi jalan yang ada.

Juga mengidentifikasi jalur pengalihan saluran air yang aman untuk daerah tersebut. Selain itu juga perhatikan kondisi jalur parit dan lubang keluar dan masuk gorong-gorong.

- Vegetasi.

Jenis tanaman dan kondisi pertumbuhan tanaman yang terjadi baik di dalam lokasi maupun yang berdekatan dengan lokasi aplikasi soil bioengineering. Hal ini terutama penting untuk mengidentifikasi spesies yang mungkin menjadi dominan.

Selain itu juga perlu dipikirkan lokasi penyiapan tanaman dan pembenihan. 


\section{- Proses erosi.}

Proses erosi yang perlu diperhatikan adalah jenis erosi permukaan yang terjadi, termasuk rembesan. Sumber bahan erosi: seperti akibat dari pemotongan lereng atau pembuatan jalan. Selain itu perlu diperhatikan juga kecenderungan lokasi tersebut untuk membaik setelah aplikasi soil bioengineering, apakah tetap atau memburuk.

\subsection{Aplikasi Soil Bioengineering}

Teknik soil bioengineering telah diterapkan di berbagai negara dan juga di Indonesia. Salah satu aplikasinya yang akan dibahas adalah untuk upaya stabilisasi lereng. Ganapathy dan Hada (2012) menerangkan bahwa teknik soil bioengineering bukan sebagai pengganti dari teknik sipil namun sebagai komplemen dalam mengatasi berbagai masalah ketidakstabilan lereng tipe dangkal. Dari sudut pandang umur antar teknik dengan struktur sipil dan dengan teknik vegetasi adalah kebalikan dimana struktur sipil umur teknisnya kian menurun sedangkan umur dengan teknik vegetasi meningkat dan menjadi lebih lama (lihat gambar 1). Hal ini apabila asumsi perawatan dilakukan secara baik. Soil bioengineering menjadi lebih kuat ketika vegetasi yang ditanam tumbuh menjadi besar. Ketika tanaman menjadi lebih besar maka sistem perakarannya pun menjadi lebih banyak. Hal ini akan memperkuat tanah itu sendiri dan menurunkan kelembaban yang berlebihan karena penyerapan oleh akar. Kondisi ini dapat memperkuat kestabilan lereng. Soil bioengineering mirip fungsinya dengan aplikasi teknik sipil. Terdapat enam fungsi teknik dari soil bioengineering ini yaitu (Ganapathy dan Hada, 2012):

1. Menangkap atau menghentikan aliran partikel tanah di permukaan.

2. Menutup atau melindungi permukaan tanah atau lereng terhadap terpaan hujan dan erosi.

3. Memberi daya dukung tanah dari kedalaman.

4. Memperkuat partikel yang lepas agar tetap pada tempatnya.

5. Memperkuat tanah dengan meningkatkan gaya kuat gesernya.

6. Meningkatkan kapaistas drainase tanah pada tanah

Teknik stabilisasi lereng dengan mengunakan vegetasi sebagai contohnya dapat kita lihat di jalur tol Cipali dan Cipularang. Pada jalur ini diterapkan salah satu atau kombinasi antara teknik sipil dan teknik vegetasi atau soil bioengineering. Pada gambar 2 dapat dilihat perlakuan lereng dengan teknik sipil dimana seluruh bagian lereng distabilkan dengan cara menutupi lereng dengan campuran semen sementara pada bagian lereng dibuat banyak pipa drainase horizontal. Di jalan tol Cipularang pada bagian kiri dan kanan jalan, dapat kita amati aplikasi kedua teknik itu baik secara kombinasi ataupun secara tersendiri (gambar 3).

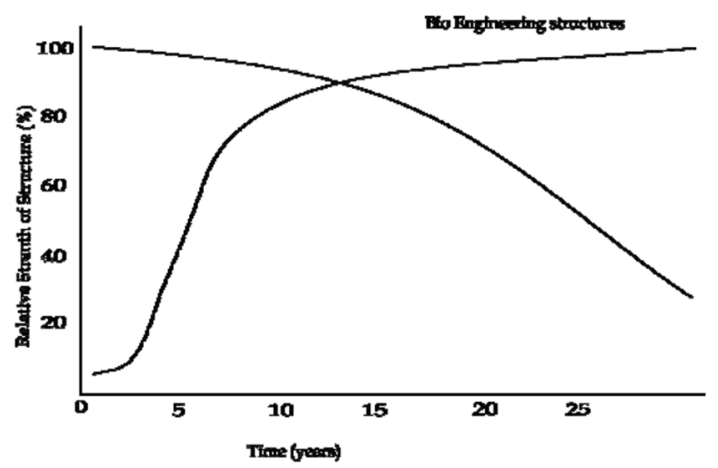

Gambar 1. Perbandingan secara umum antara umur struktur sipil dan struktur vegetatif dengan asumsi perawatan dilakukan secara baik. (Ganapathy dan Hada, 2012).

Soil bioengineering juga digunakan dalam bidang proteksi sungai. Sebagai contohnya seperti yang dilakukan oleh Rauch (2014) untuk tepi sungai yang ada di Austria. Teknik tersebut diterapkan untuk lokasi tepi sungai dengan beberapa tipe teknik sesuai kondisi segmen sungai tersebut. Pengetahuan tentang hidrolik dan morfologi sungai penting 


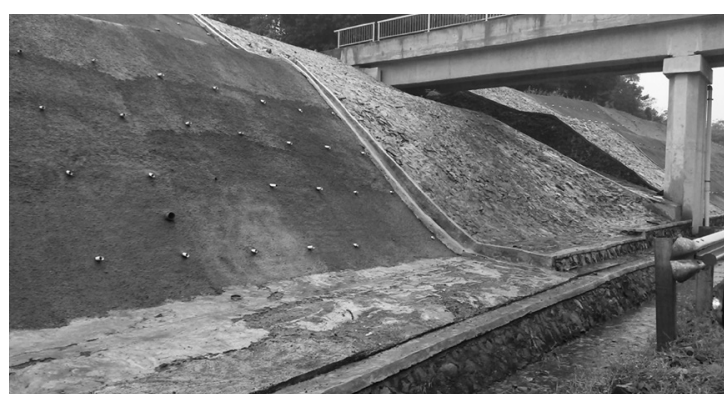

Gambar 2. Kondisi lereng di Jalan tol Cipali ke arah Palimanan. Aplikasi dengan teknik sipil.

untuk melakukan penerapan dengan teknik tersebut. Pada akhirnya teknik yang diterapkan ini ditujukan agar dapat berkontribusi pada proteksi tepi sungai serta konservasi tanah dan habitat.

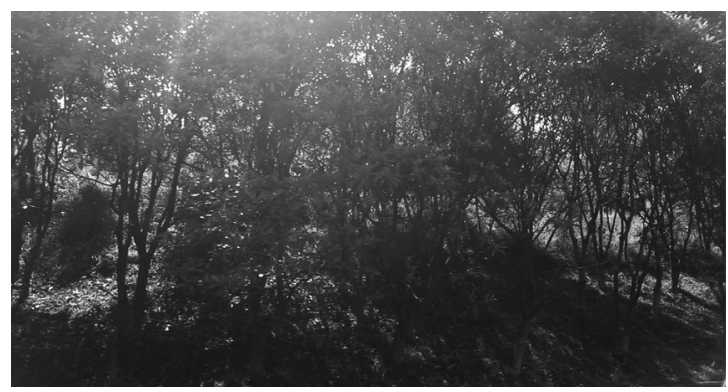

Gambar 3. Kondisi lereng di Jalan tol Cipularang ke arah Bandung. Aplikasi dengan teknik vegetasi.

Teknik soil bioengineering juga cocok untuk mitigasi risiko dan restorasi lingkungan seperti yang diterangkan oleh Petrone dan Preti (2010) yang telah menerapkan teknik ini di Nikaragua. Mereka berkesimpulan bahwa secara teknis dan sosial dan bahkan secara ekonomis, teknik ini memungkinkan untuk diterapkan di sana bahkan pada daerah yang sulit yaitu dengan memanfaatkan tenaga kerja lokal.

Lammeranner et al (2005) telah menerapkan teknik soil bioengineering ditengah pegunungan di Nepal. Teknik ini diterapkan disana dengan tujuan untuk mencegah erosi dan meningkatkan kestabilan lereng dengan menggunakan vegetasi. Seluruh jenis tanaman yang digunakan dapat tumbuh dengan baik dan jenis tanaman tersebut cocok untuk musim dingin khususnya Salix tetrasperma Roxb. dan Alnus nepalensis Don. Demikian pula Dhital et al (2013) juga telah menerapkan teknik tersebut juga di Nepal dan menerangkan bahwa peran serta dan tanggung jawab masyarakat adalah penting demi menjaga keberhasilan dan keberlangsungan program ini. Teknik ini mempunyai kelebihan yaitu lebih murah karena menggunakan material dan tenaga kerja lokal bila dibandingkan dengan aplikasi teknik sipil.
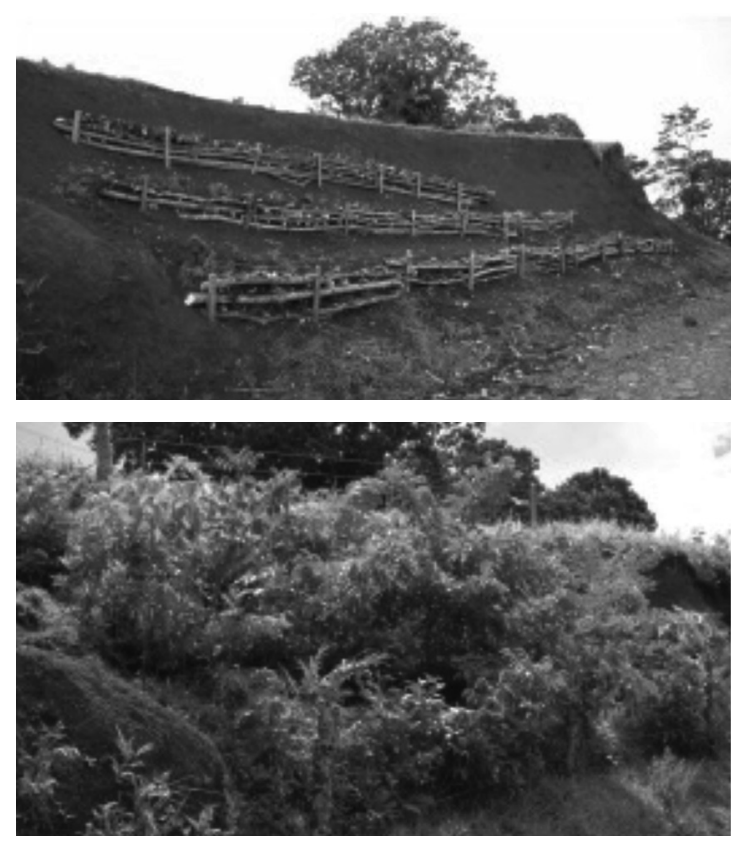

Gambar 4. Kondisi lereng dengan soil bioengineering segera setelah aplikasi (atas) dan 18 bulan setelahnya (bawah) (Petrone dan Preti 2010).

\section{KESIMPULAN}

Soil bioengineering merupakan bagian dari aplikasi dalam geologi lingkungan yang bertujuan untuk meminimalkan kerugian yang ditimbulkan atau bencana yang timbul akibat aktivitas manusia pada lingkungan geologi 
atau alam dan lahan. Pengetahuan tentang geologi lingkungan secara umum sangat penting terutama dalam mempelajari dan mengkaji kondisi proses dan sejarah suatu daerah tertentu dan kaitannya dengan aktivitas manusia dan akibat yang dapat ditimbulkan serta cara untuk mengatasi dan meminimalkan dampaknya. Soil bioengineering berguna untuk menahan erosi dan meningkatkan kestabilan lereng untuk kondisi lereng tertentu. Dalam hal kestabilan lereng, soil bioengineering merupakan opsi lain dari teknik sipil yang memiliki keuntungan umur yang lebih panjang. Namun demikian teknik soil bioengineering ini dalam penerapannya memerlukan pemikiran yang serius dan hati hati terutama dalam hal fungsinya untuk meningkatkan kestabilan lereng.

\section{DAFTAR PUSTAKA}

Bell, Fred G., 2001, Environmental Geology and Planning , Geology, Vol. V, Encyclopedia of Life Support Systems (EOLSS).

Dhital Y. P., Rijan B. K., Jiancheng Shi, 2013, Soil Bioengineering Application And Practices In Nepal, Environmental Management, February 2013, Volume 51, Issue 2, pp 354-364.

Ganapathy, G. P. dan C. L. Hada, 2012, Landslide Hazard Mitigation in the Nilgiris District, India - Environmental and Societal Issues, International Journal of Environmental Science and Development. Vol. 3, No. 5, October 2012.
Bischetti, G. B., Mario Di Fi Dio dan Florin Florineth, On the Origin of Soil Bioengineering, Journal Landscape Research, Volume 39, 2014 - Issue 5.

https://en.wikipedia.org/wiki/Soil bioengineering\#Functions_and_Effects_ of_Soil_Bioengineering_Structures, diakses 22 Februari 2016.

Lammeranner, W., H. P. Rauch, G. Laaha, 2005, Implementation and Monitoring of Soil Bioengineering Measures At A Landslide In The Middle Mountains Of Nepal, Plant And Soil, December 2005, Volume 278, Issue 1, pp 159-170.

Lewis, Lisa, 2000, Soil Bioengineering, An Alternative for Roadside Management, A Practical Guide, United States, Department of Agriculture Forest Service Technology and Development Program 7700 - Transportation Management September 20000077 1801-SDTDC.

Morgan, R. P. C. dan Rickson, R. J. (Editors), 1995, Slope Stabilization And Erosion Control: A Bio-engineering Approach, London, U.K., E. and F. N. Spon, 274 p.

Petrone, A. dan F. Preti, 2010, Soil Bioengineering For Risk Mitigation And Environmental Restoration In A Humid Tropical Area, Hydrology and Earth System Sciences, Volume 14, Issue 2, pp $239-250$.

Rauch, H. P., 2014, The Application Of Soil Bioengineering Techniques As A Part Of A Modern River Engineering Approach Restoring Hydro-Morphological, European River Restoration Conference, 6th edition, 27 - 29 October 2014, Vienna. 